\title{
GERMINAÇÃO E DESENVOLVIMENTO DE PLÂNTULAS DE Bauhinia variegata Linn.
}

\author{
GERMINATION AND DEVELOPMENT OF SEEDLING OF \\ Bauhinia variegata Linn.
}

scientific journal

v. 2 n. 22017

Recebido em 17/08/2017

Gert Jan Van de Riet ${ }^{1}$

Aceito em 30/10/2017

Samuel Alves da Silva ${ }^{2}$

Publicado em 03/11/2017

João Francisco Labres dos Santos ${ }^{3}$

Anderson Nikkel ${ }^{4}$

DOI: dx.doi.org/10.5380/biofix.v2i2.54623

Gustavo Maçaneiro 5

\author{
Universidade Federal do Paraná, Curitiba, Paraná, Brasil \\ gertjan_riet@hotmail.com ${ }^{1}$, ssilva.alves@yahoo.com.br ${ }^{2}$ \& joflabres@yahoo.com.br ${ }^{3}$ \\ Chácara Flor da Suissa, Curitiba, Paraná, Brasil \\ andersonnikkel@yahoo.com.br ${ }^{4}$ \\ Klabin S.A., Telêmaco Borba, Paraná, Brasil \\ gumacaneiro@yahoo.com.br
}

\section{RESUMO}

A espécie Bauhinia variegata é conhecida por apresentar propriedades medicinais e utilização na arborização urbana. Embora existam diversos trabalhos que tratem de métodos de quebra de dormência para espécies pertencentes ao gênero Bauhinia, o desenvolvimento das plântulas é pouco abordado. Dessa forma, o objetivo do presente estudo foi testar a eficiência de quatro métodos de quebra de dormência para sementes de $B$. variegata, considerando o desenvolvimento das plântulas em comprimento da parte aérea e da raiz. Em um delineamento inteiramente casualizado, foram testados os métodos de imersão em água aquecida $\left(80^{\circ} \mathrm{C}\right)$ por 10 minutos, escarificação mecânica com lixa no 80, desponte na região oposta à micrópila e imersão em álcool etílico $70 \%$ durante 10 minutos. Os métodos foram avaliados pela porcentagem de germinação, índice de velocidade de germinação, tempo médio de germinação, tamanho da parte aérea e raiz das plântulas. Não houve diferença estatística entre as porcentagens de germinação, indicando a não existência de dormência nas sementes. Assim, a análise do desenvolvimento inicial da parte aérea e da raiz das plântulas podem ser indicadores da influência dos tratamentos utilizados. O tratamento de desponte oposto à micrópila mostrou-se superior por apresentar o melhor desenvolvimento da parte aérea e da raiz das plântulas. Os tratamentos em álcool etílico e água quente $80^{\circ} \mathrm{C}$ não são recomendados.

PALAVRAS-CHAVE: Dormência, Escarificação, Sementes.

\section{ABSTRACT}

The species Bauhinia variegata is known to have medicinal properties and to be used in urban afforestation. While there are several studies dealing with dormancy-breaking methods for species belonging to the genus Bauhinia, seedling development is rarely discussed. Therefore, the aim of the present study was to test the efficiency of four dormancy-breaking methods for $B$. variegata seeds, considering the development of seedlings in aerial part lenght and root lenght. In a completely randomized design, the methods of immersion in heated water $\left(80^{\circ} \mathrm{C}\right)$ for 10 minutes, mechanical scarification with sandpaper $\mathrm{n} 080$ grid, splitting in the region opposite to the micropyle, and immersion in ethyl alcohol $70 \%$ for 10 minutes were tested. The methods were evaluated by the percentage of germination, germination speed index, mean germination time, aerial part size, and root size. There was no statistical difference between germination percentages, indicating the absence of seed dormancy. Consequently, the analysis of the initial development of the aerial part and root of the seedlings is an indicator of the influence of the treatments used. The treatment of splitting opposite to the micropyle was superior since it presented the best development of the aerial part and root of the seedlings. Treatments in ethyl alcohol and $80^{\circ} \mathrm{C}$ hot water are not recommended.

KEYWORDS: Dormancy, Scarification, Seeds. 


\section{INTRODUÇÃO}

A compreensão das características de reprodução das espécies florestais na natureza, como os estudos de morfologia de frutos e sementes, bem como o entendimento dos processos germinativo e de desenvolvimento das plântulas, é de fundamental importância para a produção de mudas, e, consequentemente, à viabilização da conservação e utilização dessas espécies para os mais variados fins (HALINSKI et al., 2013).

Bauhinia variegata Linn. é uma leguminosa de porte arbóreo que pode atingir $15 \mathrm{~m}$ de altura, originária da Índia, semidecídua, pertencente à subfamília Caesalpinioideae. Essa espécie apresenta flores com coloração roxa e é conhecida vulgarmente como pata-devaca, por apresentar folha simples fendida no meio, formando dois lobos que se assemelham a uma pata de bovino (LORENZI; MATOS, 2002).

De acordo com Rao et al. (2008), a espécie é conhecida por possuir propriedades medicinais e utilizada na medicina popular para o tratamento de inflamações. Mishra et al. (2013) relatam que o extrato proveniente das folhas da $B$. variegata apresenta compostos antibacterianos, antioxidantes e anticancerígenos. Segundo Jan et al. (2008), a casca da árvore é utilizada como tônico no tratamento de úlceras e doenças de pele, ao passo que a raiz pode ser utilizada como antídoto para veneno de cobra. No Brasil, segundo Frankish et al. (2010), assim como também em algumas regiões da África e da Índia, as plantas do gênero Bauhina são usadas na etnomedicina para o tratamento de diabetes.

A espécie também possui apreciação ornamental, devido às suas boas características paisagísticas, como porte médio, presença de folhas grandes, copa de largura moderada e flores com bom aspecto visual (ROSA et al., 2008). Além do Brasil, autores como Nagendra e Gopal (2010) citam o uso da espécie na arborização urbana na Índia. Zhang e Jim (2014) mencionam a grande contribuição para biodiversidade urbana de Hong Kong.

A dormência é uma adaptação de algumas espécies e funciona como mecanismo natural de resistência aos fatores adversos do meio. Assim, a semente tende a não germinar até mesmo em condições ambientais (AZEREDO et al., 2010). De acordo com Carvalho e Nakagawa (2000), a dormência é uma estratégia de perpetuação da espécie. Por impedir que as sementes germinem na mesma época, a dormência faz com que alguns indivíduos evitem a germinação em períodos inóspitos, aumentando a probabilidade de sobrevivência e diminuindo o risco de extinção da espécie.

Segundo Bewley e Black (1994), existem três tipos de dormência: imposta pelo tegumento; devido ao desenvolvimento embrionário e devido as substâncias promotoras e inibidoras. Embora seja uma estratégia adaptativa benéfica das espécies na natureza, a dormência se apresenta como um fator prejudicial para o uso dessas sementes em projetos florestais e agrícolas, uma vez que é uma restrição na produção de mudas (COSTA et al., 2010).

Com o intuito de se obter uma germinação rápida e homogênea, sementes com essa característica passam por tratamentos de quebra de dormência, os quais variam de acordo com tipo de dormência, espécie, disponibilidade de recursos e efeito sobre o desenvolvimento das plântulas. Em vista disso, considerando que a dormência das sementes da $B$. variegata é do tipo tegumentar (ALVES et al., 2000), os tratamentos para superação da dormência têm como objetivo fragilizar o tegumento da semente (ALBUQUERQUE et al., 2007).

O desenvolvimento das plântulas tem profunda ligação com a qualidade das mudas produzidas e consequentemente com o sucesso do empreendimento no qual as mesmas serão utilizadas. Embora existam diversos estudos a respeito da quebra de dormência para espécies do gênero Bauhinia, os efeitos dos tratamentos sobre o desenvolvimento são pouco abordados.

Dessa forma, considerando que avanços no cultivo da respectiva espécie podem trazer benefícios ambientais, sociais e econômicos para sociedade, o objetivo do presente estudo foi testar quatro métodos de quebra de dormência para sementes de $B$. variegata, provenientes da arborização urbana do município de Curitiba, e analisar os efeitos sobre o desenvolvimento das plântulas.

\section{MATERIAL E MÉTODOS}

As sementes de $B$. variegata foram coletadas de 48 árvores matrizes da arborização urbana de Curitiba no bairro Jardim Botânico, antes da deiscência das vagens, no mês de novembro de 2012. Imediatamente após a coleta, foi realizada a seleção das sementes consideradas viáveis, visando remover impurezas e eliminar microrganismos que possam interferir na germinação das sementes. Em seguida, foi feita a desinfestação das sementes com Hipoclorito de Sódio ( $\mathrm{NaOCl}$ ), na concentração de $2 \%$, por 30 minutos.

Foi realizada a pesagem das sementes conforme o procedimento nas Regras de Análises de Sementes 
(BRASIL, 2009). Para o cálculo do peso de mil sementes (PMS), foram feitas pesagens de oito subamostras com 100 sementes cada. Em seguida, foi calculada a média e efetuada sua extrapolação para 1.000 sementes. Não foi avaliada a umidade das sementes.

O experimento consistiu em oito repetições de 25 sementes, totalizando 200 por tratamento. As sementes foram submetidas aos seguintes tratamentos: (1) sementes intactas (testemunha); (2) imersão em água aquecida a $80^{\circ} \mathrm{C}$ por 10 minutos; (3) escarificação mecânica (lixa no 80); desponte na região oposta à micrópila; imersão em álcool etílico $70 \%$ durante 10 minutos.

Depois de submetidas aos tratamentos, instalou-se o experimento em caixas gerbox, contendo substrato vermiculita de granulometria média, em um germinador à temperatura de $30^{\circ} \mathrm{C}$, onde as sementes foram umedecidas regularmente em cada gerbox com $50 \mathrm{~mL}$ de água no primeiro e quarto dia.

A verificação do número de sementes germinadas iniciou-se após a implantação do experimento, estendendo até o 20 dia após a semeadura, sendo a germinação considerada efetiva a partir da protrusão da raiz primária com cerca de $2 \mathrm{~mm}$. A germinação foi avaliada pela porcentagem de germinação e pelo índice de velocidade de germinação (1), segundo Maguire (1962).

$\mathrm{IVG}=\frac{\mathrm{G}_{1}}{\mathrm{~N}_{1}}+\frac{\mathrm{G}_{2}}{\mathrm{~N}_{2}}+\frac{\mathrm{G}_{3}}{\mathrm{~N}_{3}}+\cdots \frac{\mathrm{G}_{\mathrm{n}}}{\mathrm{N}_{\mathrm{n}}}$

Em que: IVG = índice de velocidade de germinação; $\mathrm{G}=$ número de sementes germinadas; e $\mathrm{N}=$ número de dias após implantação do experimento.

Também foi verificado o tempo médio de cada repetição e depois o tempo médio de germinação (TMG) de cada tratamento. A germinação total das sementes de todos os tratamentos ocorreu no 8 o dia de avaliação, quando foi realizada a medição do comprimento total da parte aérea e da raiz de cada plântula, cuja radícula apresentava mais de $0,5 \mathrm{~cm}$ de comprimento.

O comprimento da parte aérea foi medido do colo até a gema apical, ao passo que, para medição da raiz, mensurou-se do colo até a extremidade final da raiz primária, com objetivo de verificar se os diferentes tratamentos influenciaram no vigor de crescimento das mesmas.

Em um delineamento inteiramente casualizado, primeiramente aplicou-se o teste de Bartlett para constatação da homogeneidade da variância, seguido da análise de variância (ANOVA). Para significância do teste $F$, utilizou-se o teste de médias de Tukey a $5 \%$ de probabilidade para verificação da diferença estatística entre as médias. Todo o processo estatístico foi realizado com o auxílio do programa Assistat versão 7.7 (SILVA; AZEVEDO, 2016).

\section{RESULTADOS E DISCUSSÃO}

$O$ peso médio de 1.000 sementes de $B$. variegata foi igual a 246,13 g, o que representa 4.063 sementes por quilo, não sendo calculado o teor de umidade. 0 número de sementes foi inferior ao encontrado por Lopes et al. (2007), de 5.922 sementes por quilo para a mesma espécie. Os dados referentes à porcentagem de germinação e ao IVG encontram-se na Tabela 1.

Tabela 1. Médias da porcentagem de germinação, índice de velocidade de germinação (IVG), tempo médio de germinação (TMG) da parte aérea e do comprimento da raiz de $B$. variegata

\begin{tabular}{ccccccc}
\hline Tratamentos & $\begin{array}{c}\text { Germinação } \\
\text { (\%) }\end{array}$ & IVG & TMG & $\begin{array}{c}\text { Aérea } \\
\text { (cm) }\end{array}$ & $\begin{array}{c}\text { Raiz } \\
\text { (cm) }\end{array}$ \\
\hline T1 & $99,5 \mathrm{a}$ & $9,49 \mathrm{~b}$ & $2,98 \mathrm{a}$ & $2,19 \mathrm{~b}$ & $5,83 \mathrm{~b}$ \\
T2 & $100 \mathrm{a}$ & $16,43 \mathrm{a}$ & $1,93 \mathrm{~b}$ & $2,40 \mathrm{~b}$ & $6,31 \mathrm{a}$ \\
T3 & $100 \mathrm{a}$ & $16,75 \mathrm{a}$ & $1,88 \mathrm{~b}$ & $2,99 \mathrm{a}$ & $6,54 \mathrm{a}$ \\
\hline Média & $99,0 \mathrm{a}$ & $8,16 \mathrm{~b}$ & $3,13 \mathrm{a}$ & $0,54 \mathrm{c}$ & $4,21 \mathrm{c}$ \\
\hline Desvio padrão & 0,48 & 4,52 & 0,40 & 1,05 & 1,05 \\
\hline CV\% & 0,5 & 35,6 & 16,8 & 51,7 & 18,4 \\
\hline
\end{tabular}

T1 = testemunha; T2 = lixa no 80; T3 = desponte; T4: =álcool etílico; $\mathrm{CV} \%$ = coeficiente de variação; e médias seguidas pela mesma letra não diferem entre si pelo teste de Tukey considerando-se o nível de significância de 5\%.

No tratamento de imersão em água aquecida a $80^{\circ} \mathrm{C}$, constatou-se a morte de todas as sementes. Assim, supõe-se que a quebra de dormência com água aquecida não é recomendável para sementes de espécies do respectivo gênero. Isso contraria as recomendações de Carvalho (1994), o qual relata que, embora muitas sementes de $B$. variegata germinam sem tratamento, a maioria delas necessita de tratamento pré-germinativo de imersão em água aquecida $\left(80^{\circ} \mathrm{C}\right)$, bem como permanência na água fora do aquecimento por 10 minutos para embebição das sementes.

Notou-se elevados valores de porcentagem de germinação, com média de $99,63 \%$ e ausência de 
diferença estatística. Lopes et al. (2007) realizaram um trabalho semelhante com sementes de duas espécies pertencentes ao gênero Bauhinia, os quais observaram germinação de $70 \%$ no tratamento testemunha e de $0 \%$ em tratamento com água aquecida a $97^{\circ} \mathrm{C}$. A maior taxa de germinação foi observada no tratamento de escarificação mecânica, com $98 \%$ de germinação e próximo ao encontrado no presente estudo. MartinelliSeneme et al. (2006) constataram que sementes de $B$. variegata embebidas em água fria durante duas horas apresentam resultados semelhantes aos dos tratamentos de escarificação mecânica.

Em relação ao IVG, foi possível observar que os tratamentos de escarificação mecânica (lixa e desponte) proporcionaram os melhores resultados, enquanto o tratamento com álcool etílico não diferiu da testemunha.

A eficácia da escarificação mecânica na superação da dormência também foi observada por Alves et al. (2000) para sementes da espécie Bauhinia ungulata L., para a qual apresentou as maiores taxas de germinação. Desse modo, presume-se que seja o tratamento mais indicado para a quebra de dormência. A Figura 1 apresenta o processo de germinação das sementes de cada tratamento ao longo do tempo.

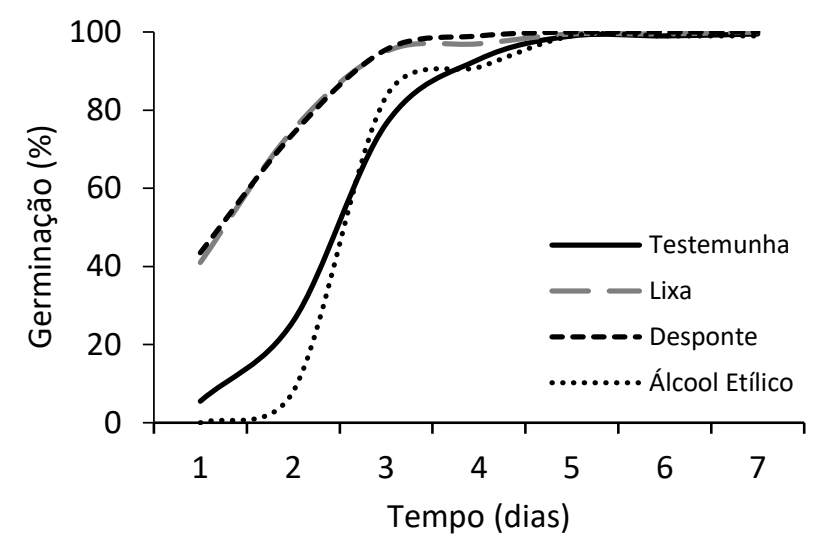

Figura 1. Influência dos tratamentos na germinação das sementes $B$. variegata.

Quanto à porcentagem de germinação das sementes (Figura 1), se observou que, no primeiro dia, os tratamentos com lixa e desponte apresentaram respectivamente $41 \%$ e $43,5 \%$ de germinação, a testemunha resultou $5,5 \%$ e o álcool etílico não apresentou germinação. No segundo dia, as sementes tratadas com lixa e desponte tiveram germinações de respectivamente $75 \%$ e $74 \%$; a testemunha apresentou $26 \%$ e o álcool mostrou baixa velocidade de germinação, com apenas $8 \%$. Todos os tratamentos apresentaram crescimento em parte aérea e raiz no segundo dia. No terceiro dia, apenas a testemunha apresentou germinação mais baixa, de $76,5 \%$, enquanto a lixa e o desponte mostraram aumento para $95 \%$ e $95,5 \%$, respectivamente, e 83,5\% para o álcool etílico.

No que se refere ao TMG, foi possível observar que houve diferença estatística entre as médias da germinação das sementes, segundo os respectivos tratamentos. Para Martinelli-Seneme et al. (2006), a velocidade de germinação em laboratório também foi maior quando as sementes foram escarificadas com lixa e despontadas com tesoura, porém, assim como no presente estudo, os respectivos autores não encontraram diferença estatística entre as velocidades de germinação.

Em um trabalho de Smiderle e Luz (2010), ao realizarem a quebra de dormência com embebição em álcool etílico por 5, 10 e 15 minutos, houve aumento na velocidade de germinação em todos os tratamentos em relação à testemunha, sendo que a embebição por 10 minutos foi a melhor alternativa para o uso do álcool. A diferença de resultados encontrada neste estudo pode estar relacionada com a rápida lavagem posterior das sementes em água corrente.

Ao analisar o comprimento da parte aérea, observouse que as sementes com desponte atingiram em média $2,99 \mathrm{~cm}$, aproximadamente $0,8 \mathrm{~cm}$ superior ao da testemunha. Esse comportamento provavelmente está relacionado com as germinações terem ocorrido antes. Porém, o valor encontrado é inferior ao observado por Mwase e Mvula (2011) no mesmo período de avaliação e utilizando o mesmo tratamento para Bauhinia thonningii Schumach., de aproximadamente $5 \mathrm{~cm}$ para sementes pequenas e de $8 \mathrm{~cm}$ para as grandes.

Resultados superiores à testemunha para o crescimento da raiz foram encontrados para os tratamentos com lixa e desponte da região oposta a micrópila. 0 tratamento com álcool etílico apresentou o pior resultado na medição da parte aérea e na raiz 0,54 $\mathrm{cm}$ e 4,21 cm, respectivamente. Com isso, observa-se que, embora o tratamento com álcool tenha apresentado boa porcentagem de germinação, presume-se que tenha afetado negativamente o desenvolvimento das plântulas.

\section{CONCLUSÕES}

Não há diferença estatística entre as porcentagens de germinação, indicando a não existência de dormência nas sementes. Contudo, as análises do desenvolvimento inicial da parte aérea e raiz das plântulas são indicadores da influência dos tratamentos utilizados. 
Com base nessa premissa, o tratamento de desponte oposto à micrópila mostra-se superior aos demais, uma vez que proporciona o melhor desenvolvimento da parte aérea e raiz das plântulas. Os tratamentos em álcool etílico e água quente 80 C não são recomendados.

\section{REFERÊNCIAS}

ALBUQUERQUE, K. S.; GUIMARÃES, R. M.; ALMEIDA, I. F.; CLEMENTE, A. D. C. S. Métodos para a superação da dormência em sementes de sucupira-preta (Bowdichia virgilioides Kunth.). Ciência e Agrotecnologia, v. 31, n. 6, p. 1716-1721, 2007.

ALVES, M. D.; MEDEIROS FILHO, S.; ANDRADE-NETO, M.; TEÓFILO, E. M. Superação da dormência em sementes de Bauhinia monandra Britt e Bauhinia ungulata L.Caesalpinoideae. Revista Brasileira de Sementes, v. 22, n. 2, p. 139-144, 2000.

AZEREDO, G. A. D.; PAULA, R. C. D.; VALERI, S. V.; MORO, F. V. Superação de dormência de sementes de Piptadenia moniliformis Benth. Revista Brasileira de Sementes, v. 32, n. 2, p. 49-58, 2010.

BEWLEY, J. D.; BLACK, M. Seeds: physiology of development and germination. New York: Plenum Press, 1994. 445 p.

BRASIL. Ministério da Agricultura, Pecuária e Abastecimento. Regras para análise de sementes. Brasília: Mapa/ACS, 2009. $395 \mathrm{p}$.

CARVALHO, P. E. R. Espécies florestais brasileiras: recomendações silviculturais, potencialidades e uso da madeira. Brasília: EMBRAPA-CNPF/SPI, 1994. 640 p.

CARVALHO, N. M.; NAKAGAWA, J. Sementes: ciência, tecnologia e produção. 4. ed. Jaboticabal: FUNEP, 2000. 588 p.

COSTA. P. A.; SILVA LIMA, A. L. D.; ZANELLA, F.; FREITAS, H. D. Quebra de dormência em sementes de Adenanthera pavonina $\mathrm{L}$. Pesquisa Agropecuária Tropical, v. 40, n. 1, p. 83-88, 2010.

FRANKISH, N.; SOUSA, M. F.; MILLS, C.; SHERIDAN, H. Enhancement of insulin release from the $\beta$-cell line INS-1 by an ethanolic extract of Bauhinia variegata and its major constituent roseoside. Planta Medica, v. 76, n. 10, p. 995-997, 2010.

HALINSKI, S. L.; COSMO, N. L.; GOGOSZ, A. M.; REGO, S. S.; NOGUEIRA, A. C.; KUNYOSHI, Y. S. Caracterização morfológica de frutos, sementes, plântulas e germinação de sementes de Casearia decandra. Pesquisa Florestal Brasileira, v 33, n. 75, p. 253-259, 2013.

JAN, S.; KHAN, M. A.; DIN, S. U.; MURAD, W.; HUSSAIN, M.; GHANI, A. Herbal remedies used for gastrointestinal disorders in Kaghan valley, NWFP, Pakistan, Pakistan Journal of Weed Science Research, v. 14, n. 4, p. 169-200, 2008.

LOPES, J. C.; BARBOSA, L. G.; CAPUCHO, M. T. Germinação de sementes de Bauhinia spp. Revista Floresta, v. 37, n. 2, p. 265-274, 2007.
LORENZI, H.; MATOS, F. J. Plantas medicinais no Brasil: nativas e exóticas. Nova Odessa: Instituto Plantarum, 2002. 368 p.

MAGUIRE, J. D. Speed of germination-aid in selection and evaluation for seedling emergence and vigor. Crop Science, v. 2, n. 1, p. 176-177, 1962.

MARTINELLI-SENEME, A.; POSSAMAI, E.; SCHUTA, L. R.; VANZOLINI, S. Germinação e sanidade de sementes de Bauhinia variegata. Revista Árvore, v. 30, n. 5, p. 719-724, 2006.

MISHRA, A.; SHARMA, A. K.; KUMAR, S.; SAXENA, A. K.; PANDEY, A. K. Bauhinia variegata leaf extracts exhibit considerable antibacterial, antioxidant, and anticancer activities. BioMed Research International, v. 2013, 2013.

MWASE, W. F.; MVULA, T. Effect of seed size and pre-treatment methods of Bauhinia thonningii Schum. on germination and seedling growth. African Journal of Biotechnology, v. 10, n. 13, p. 5143-5148, 2011.

NAGENDRA, H.; GOPAL, D. Street trees in Bangalore: density, diversity, composition and distribution. Urban Forestry \& Urban Greening, v. 9, n. 2, p. 129-137, 2010.

RAO, Y. K.; FANG, S. H.; TZENG, Y. M. Antiinflammatory activities of flavonoids and a triterpene caffeate isolated from Bauhinia variegate. Phytotherapy Research, v. 22, n. 7, p. 957-962, 2008.

ROSA, D. D.; BASSETO, M. A.; OHTO, C. T.; SOUZA, H. G.; SOUZA, N. L.; FURTADO, E. L. Ocorrência de oídio (Oidium caesalpiniacearum Hosag \& W. Braum) em pata de vaca (Bauhinia forficata Link.) no Brasil. Summa Phytopathologica, v. 34, n. 2, p. 196, 2008.

SILVA, F. A. S.; AZEVEDO, C. A. V. The Assistat software version 7.7 and its use in the analysis of experimental data. African Journal of Agricultural Research, v. 11, n. 39, p. 3733-3740, 2016.

SMIDERLE, O. J.; LUZ, F. J. F. Superação da dormência em sementes de pata-de-vaca (Bauhinia angulata Vell). Revista Agro@mbiente On-line, v. 4, n. 2, p. 80-85, 2010.

ZHANG, H.; JIM, C. Y. Contributions of landscape trees in public housing estates to urban biodiversity in Hong Kong. Urban Forestry \& Urban Greening, v. 13, n. 2, p. 272-284, 2014. 